\title{
Fabrication and Corrosion Resistance of Mg-Zn-Y-based Nano-quasicrystals Alloys
}

\author{
Zhifeng Wang ${ }^{\mathrm{a}, \mathrm{b}}$, Weimin Zhao $^{\mathrm{a}}{ }^{*}$, Chunling Qin ${ }^{\mathrm{a}}$, Yan Cui ${ }^{\mathrm{a}}$ \\ ${ }^{a}$ School of Materials Science and Engineering, Hebei University of Technology, Tianjin 300130, China \\ ${ }^{\mathrm{b}}$ Light Metals Group, Korea Institute of Materials Science, Changwon 642-831, Republic of Korea
}

Received: April 17, 2011; Revised: December 19, 2011

\begin{abstract}
A wedge-shaped copper mold was used to fabricate micro quasicrystals(QCs). Stable Mg-Zn-Ybased nano-QCs were directly synthesized through this simple route instead of crystallization from metallic glasses or complicated forming processes at high temperature. The study showed that on the tips of the wedge-shaped ingots, the minimum diameter of nano-QCs approach to $4 \sim 6 \mathrm{~nm}$. The main size of nano-QCs is about 10 30 nm. The maximum microhardness of QCs has been dramatically improved to about HV440 which increased by about $280 \%$ compared with that of the petal-like QCs fabricated under common cast iron mold cooling conditions. Possessing a certain negative enthalpy of mixing and existence of Frank-Kasper-type phases determined the formation of Mg-Zn-Y-based nano-QCs. The further electrochemical studies showed that $\mathrm{Mg}_{71} \mathrm{Zn}_{26} \mathrm{Y}_{2} \mathrm{Cu}_{1}$ nano-QC alloy possess high corrosion resistance in simulated seawater and its corrosion resistance is much better than those of the $\mathrm{Mg}_{72} \mathrm{Zn}_{26} \mathrm{Y}_{2}$ and $\mathrm{Mg}_{71} \mathrm{Zn}_{26} \mathrm{Y}_{2} \mathrm{Cu}_{0.5} \mathrm{Ni}_{0.5}$ nano-QC alloys.
\end{abstract}

Keywords: nano-quasicrystals, magnesium alloy, Mg-Zn-Y-based alloys, wedge-shaped mold

\section{Introduction}

Quasicrystals(QCs) are aperiodic solids and display a rotational symmetry (typically five- or ten-fold) which is forbidden within the realm of conventional crystallography ${ }^{1}$. The first example was obtained as a metastable icosahedral configuration in a rapidly solidified Al-Mn alloy ${ }^{2}$. The unexpected discovery of QCs presented scientists with a new, puzzling class of materials and involved hundreds of researchers in this realm.

The preparation of nano-quasicrystal(nano-QC) phase mainly has two ways at present. Nano-QCs are known to form in annealed $\mathrm{Zr}$-based ${ }^{3,4}$ and Al-based ${ }^{5}$ metallic glasses. Moreover, they can also be fabricated in extruded or wrought Mg-based alloys at high temperature ${ }^{6,7}$. Embedded QCs in a matrix can cause significant improvement in mechanical properties. So these nano-QC alloys exhibit better mechanical properties compared with their corresponding glasses or alloys. However, these nano-QCs prepared from previous processing crafts at elevated temperature are meta-stable. That results in decreasing improvement effect coming from nano-QCs. In the present study, we show the formation of stable nano-QC phase through a simple route.

On the other hand, magnesium alloys possess poor corrosion resistivity. They can easily be eroded either in acid, neutral or alkali solutions, even in pure water ${ }^{8}$. So, their further applications were restrained. It is reported that rapidly solidified $\mathrm{Mg}-\mathrm{Zn}-\mathrm{Y}$ alloy bars and ribbons exhibited excellent corrosion resistance ${ }^{9}$. Considering the excellent corrosion resistance of QCs, we managed to synthesis nano-QCs in a relatively high cooling rate. NanoQCs containing magnesium alloy are hopeful to show their improved corrosion resistance properties.

*e-mail:wmzhao@yahoo.com
In past work, we synthesized quarternary spherical $\mathrm{Mg}$ $\mathrm{Zn}-\mathrm{Y}-\mathrm{Cu}$ QC phase ${ }^{10}$ with its diameter of about $2 \mu \mathrm{m}$ by controlling degree of undercooling of the melts. In order to fabricate nanoscale QCs, we improved the cooling condition in this paper by using a wedge-shaped copper mold ${ }^{11}$ and adjusted the components of the alloys. The multiplex spherical nano-QCs are successfully synthesized and their electrochemical properties were researched in simulated seawater. The role of nano-QCs in improving the mechanical properties $^{12}$ and corrosion resistance of Mg-based alloys were discussed.

\section{Experimental}

The experimental alloys (nominal compositions are listed in Table 1) were produced by a reformed crucible electric resistance furnace $\left(\mathrm{SG}_{2}-5-10 \mathrm{~A}\right.$, China), melted under the mixture of $\mathrm{SF}_{6} / \mathrm{CO}_{2}$ protective atmosphere, using $\mathrm{Mg}(99.95 \%), \mathrm{Zn}(99.90 \%)$ and $\mathrm{Y}(99.99 \%)$ ingots; $\mathrm{Cu}(99.99 \%)$ and $\mathrm{Ni}(99.99 \%)$ powder. Stirring for 2 minutes by impellor at $1073 \mathrm{~K}$ and holding for 5 minutes above $1053 \mathrm{~K}$, the melt was poured and cooled in a wedgeshaped water-cooled copper mold. The size of the ingot and sample position is shown in Figure 1. The microstructures of the specimens were investigated with scanning electron microscopy (SEM, HITACHI S4800, Japan) and transmission electron microscopy (TEM, DEOL JEM2100, Japan). Micro-hardness of quasicrystals-containing experimental alloys was examined by micro-hardness tester (HXD-1000, China). The electrochemical properties of specimens were tested in simulated seawater $(2.73 \%$ $\mathrm{NaCl}, 0.24 \% \mathrm{MgCl}_{2}, 0.34 \% \mathrm{MgSO}_{4}, 0.11 \% \mathrm{CaCl}_{2}, 0.08 \%$ $\mathrm{KCl}, 96.5 \%$ deionized water, vol. (\%)) by electrochemical 
Table 1. Nominal composition of the experimental alloys.

\begin{tabular}{ccccccc}
\hline \multicolumn{6}{c}{ Specimen N $^{\text {. }}$} & \multicolumn{5}{c}{ Alloy compositions (at. \%) } \\
\hline Middle & Tip & Mg & Zn & Y & Cu & Ni \\
\hline 1\# & $4 \#$ & 72.0 & 26.0 & 2.0 & - & - \\
$2 \#$ & $5 \#$ & 71.0 & 26.0 & 2.0 & 1.0 & - \\
$3 \#$ & $6 \#$ & 71.0 & 26.0 & 2.0 & 0.5 & 0.5 \\
\hline
\end{tabular}

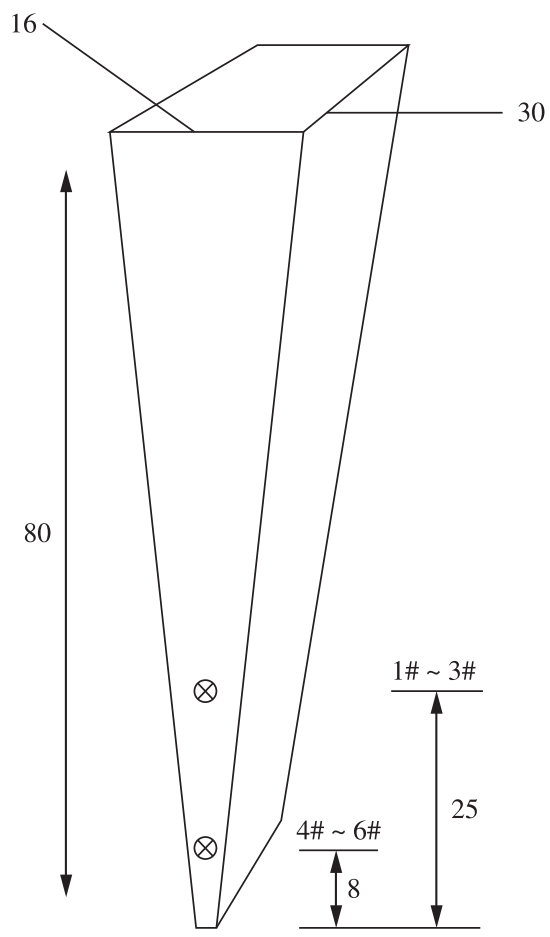

Figure 1. Schematic of the wedge-shaped ingot. Sample positions are indicated. Unit of length: $\mathrm{mm}$.

workstation (Gamry, PCI4-750, USA) with a sweep rate of $10 \mathrm{mV} . \mathrm{s}^{-1}$. The reference electrode was the saturated calomel electrode (SCE).

\section{Results and Discussion}

\subsection{Fabrication of micro $Q C s$}

A typical morphology and size of a QC solidified in a cast iron mold is petal-like and about $12 \mu \mathrm{m}$, respectively ${ }^{13}$. In previous work, the spherical QC phase with its diameter of about $2 \mu \mathrm{m}$ was successfully synthesized by controlling degree of undercooling of the melts ${ }^{10}$. It was reported that the smaller the spherical QC, the higher the microhardness ${ }^{14}$. So one purpose of this paper is to fabricate spherical QCs and make their size as small as possible.

Figure 2 shows SEM images of the samples taking from the middle of ingots. Thanks to the higher cooling rate getting from this wedge-shaped mold, plenty of QCs with their diameters less than $2 \mu \mathrm{m}$ were fabricated. We can see from Figure 2 and Figure 3, although the additions of $\mathrm{Cu}$ minished the volume fraction of QCs in alloys, they made QCs smaller and more round. Moreover, the mixed additions of $\mathrm{Cu}$ and $\mathrm{Ni}$ further decreased the diameter of QCs and increased the volume fraction compared with the single additions of $\mathrm{Cu}$. These phenomenon can be attribute to the improved degree of constitutional supercooling inducing from the elements $\mathrm{Cu}$ and $\mathrm{Ni}^{10,13}$. The microhardness of QCs becomes higher with the decreasing diameter of QCs. From the statistics of the distribution of particle diameters determined from Figure 2, the main size of QCs dropped from $1.2 \sim 1.5 \mu \mathrm{m}$ to $0.6 \sim 1.0 \mu \mathrm{m}$, and finally cut down to $500 \sim 800 \mathrm{~nm}$. There are also some QCs about $200 \mathrm{~nm}$ were observed in specimen $1 \# \sim 3 \#$. So on the tip of ingots, the minimum diameter of QCs is hopeful to be refreshed.

Figure 4 shows TEM images of a nano-QC in Specimen 4\#. The QC diameter is about $300 \mathrm{~nm}$. Its SAED pattern display a five-fold rotational symmetry which identify the spherical phase is indeed the QC phase. Figure 5 shows TEM images of Specimen 5\# and 6\#. The main size of nanoQCs is $12 \sim 18 \mathrm{~nm}$ and 12 16 nm respectively in Specimen $5 \#$ and $6 \#$. The number of nano-QCs is the highest and the diameter of nano-QCs is the smallest in Specimen 6\# among Specimen 4\#, 5\# and 6\#. The minimum diameter of nano-QCs synthesized in this route approach to 4 or $6 \mathrm{~nm}$. The microhardness of nano-QCs in Specimen 4\#, $5 \#$ and 6\# increased dramatically compared to that of QCs in Specimen 1\#, 2\# and 3\#, respectively. The maximum value of microhardness of nano-QCs approach to HV440 (as shown in Figure 6) in Specimen 6\# which increased by about $140 \%$ compared with that of QCs in Specimen $1 \#$ and increased by about $280 \%$ compared with that of the petal-like QCs fabricated under cast iron mold cooling conditions ${ }^{11}$.

\subsection{Forming mechanisms of nano-QCs}

The solidification process of QC phases which consists of grain nucleation and their subsequent growth is similar to that of crystals forming process. Lower cooling rate might not effectively suppress the crystallization and would result in the formation of crystal phase while higher cooing rate might suppress the nucleation and growth of the QC phase and would result in the formation of amorphous phase. So, it is necessary to properly control the cooling rate for the formation of the QC phase. Shechtman ${ }^{2}$ pointed out that the solidification rate for forming quasicrystals ought to high enough; however, it must low enough at the same time. For alloys with the certain constituent, an optimum cooling rate exists during QC formation. When the cooling rate exceeds the critical point, the QC nucleation will be restrained and amorphous maybe form for there's no time to nucleation. For rapid solidification conditions, the cooling rate will overrun the critical point, so the formation of QCs will be suppressed. On the contrary, if the cooling rate is below the critical point, with its increasing, based on the classical nucleation theory, the dynamic supercooling of the alloys will increase, and the nucleation rate will be improved rapidly. Thus, the content of QC phases will enlarge and the growth of the crystal phases will be repressed. Under the wedge-shaped copper mold cooling conditions in this paper, the cooling rate is just below the critical point. So the micro QCs can 


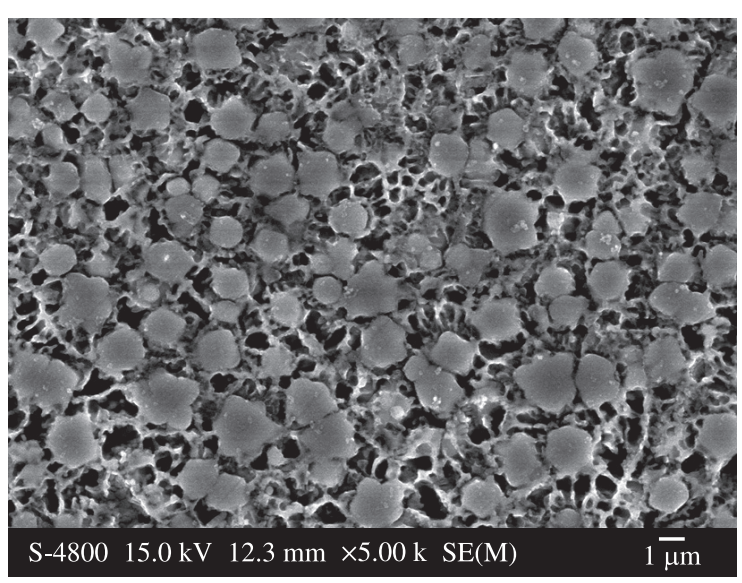

(a)

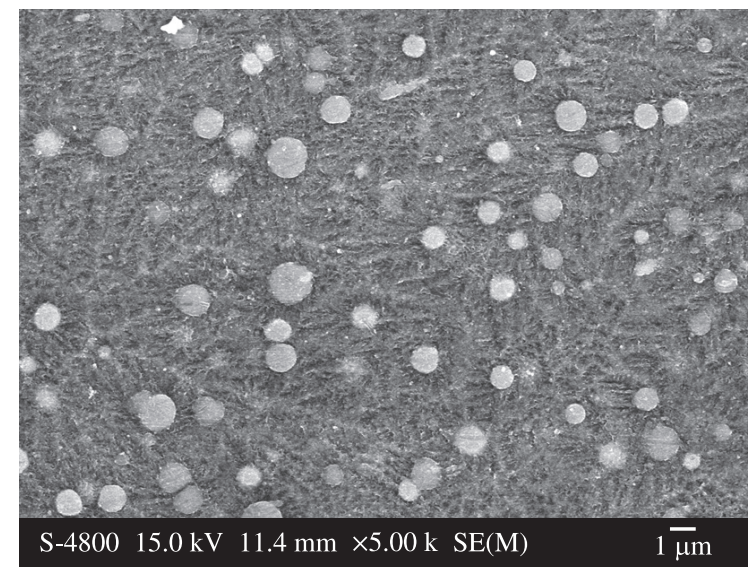

(d)

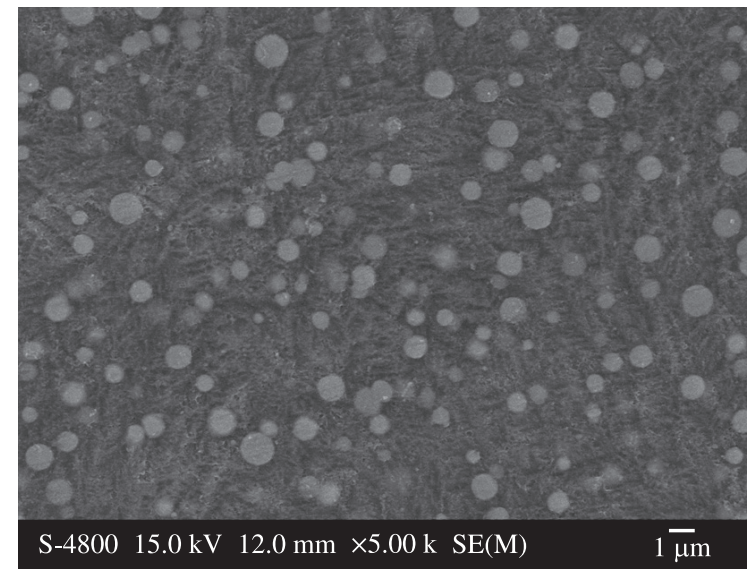

(e)

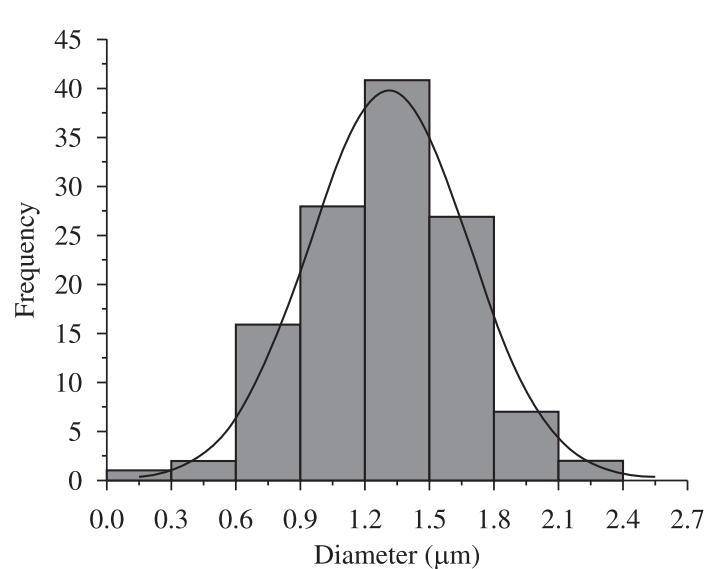

(b)

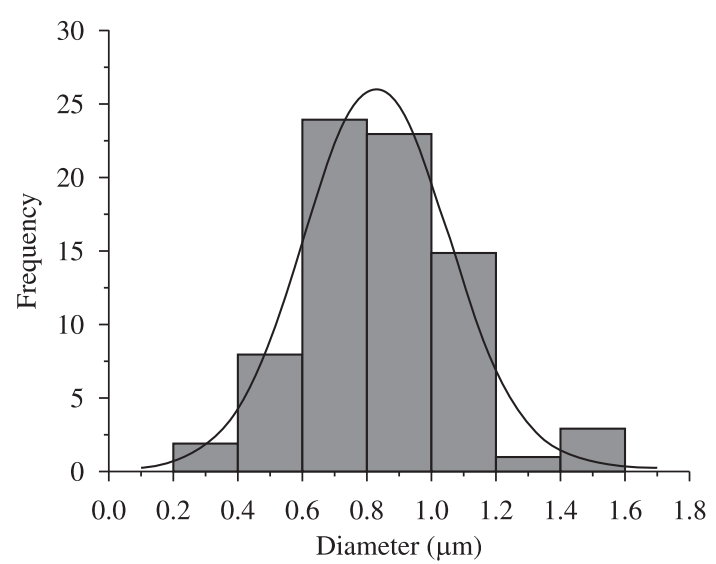

(d)

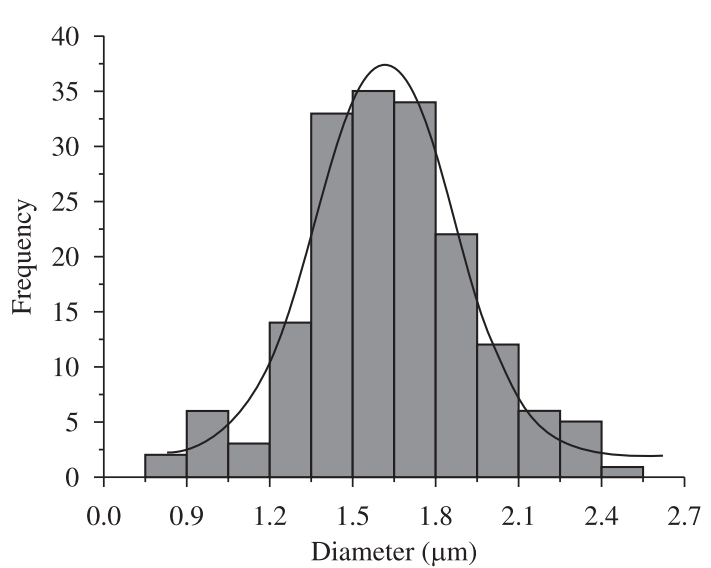

(f)

Figure 2. SEM images of the samples. a) Specimen 1\#; c) Specimen 2\#; and e) Specimen 3\#. b, d and f) are the distribution of particle diameters of Specimen 1\#, 2\# and 3\#, respectively.

be fabricated successfully, moreover, nanoscale QCs were also synthesized in this route.

On the other hand, it was reported that a large negative enthalpy of mixing and/or existence of Frank-Kasper-type phases appear to be the crucial criteria for the formation of nanoquasicrystalline phase in any system ${ }^{15}$. Meanwhile,
Mg-Zn-Y-based QCs just belong to Frank-Kasper-type phases ${ }^{16}$ and have a certain negative enthalpy of mixing. So theoretically, Mg-Zn-Y-based nano-QCs can be formed in a proper cooling conditions. The past cooling rate the researchers made to produce QCs was whether too high or too low, and was not content with the forming conditions 
of nano-QCs. This route is just meet the demands of the forming conditions of nanoscale QCs. So, nano-QCs were successfully produced in this paper.

Moreover, the additions of $\mathrm{Cu}$ and $\mathrm{Ni}$ improved the degree of constitutional supercooling of $\mathrm{Mg}-\mathrm{Zn}-\mathrm{Y}$ melts

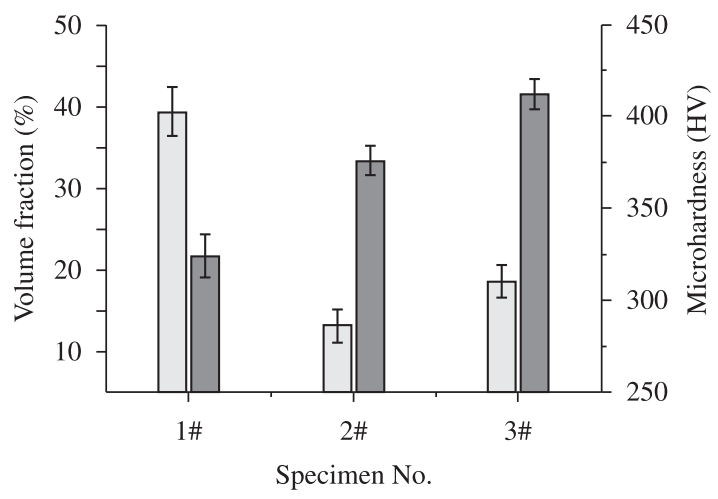

$\square$ Volume fraction $\square$ Microhardness I Error bar

Figure 3. Micro-hardness and volume fraction of the QCs.

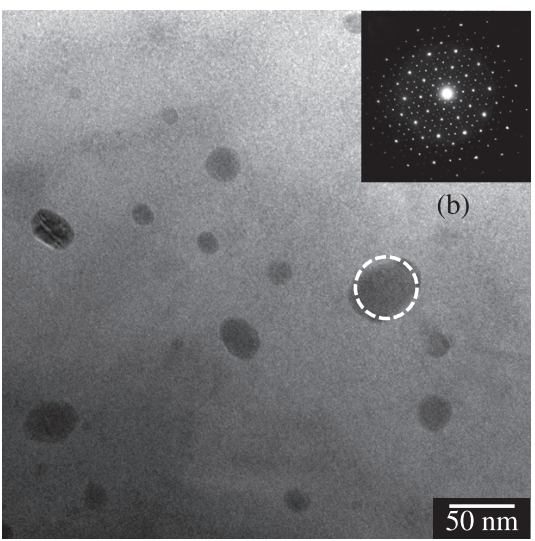

(a)

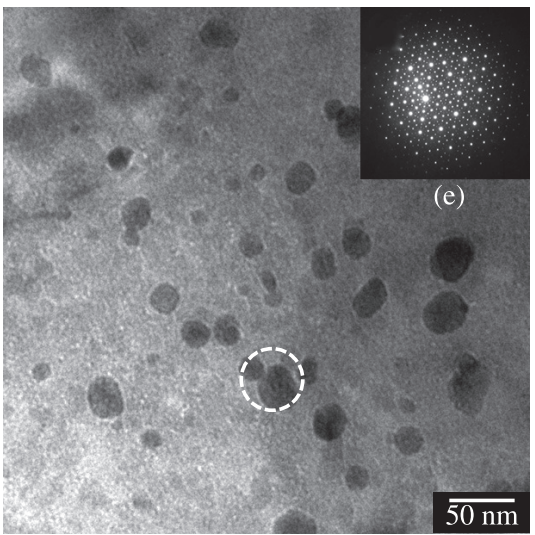

(d)

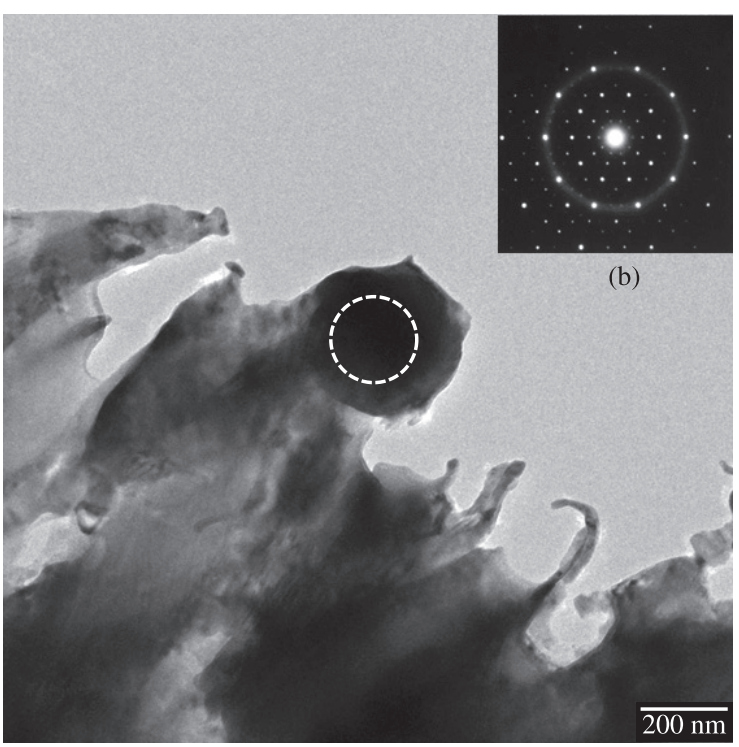

(a)

Figure 4. TEM image of Specimen 4\#: $a$ and b) QC's corresponding SAED pattern.

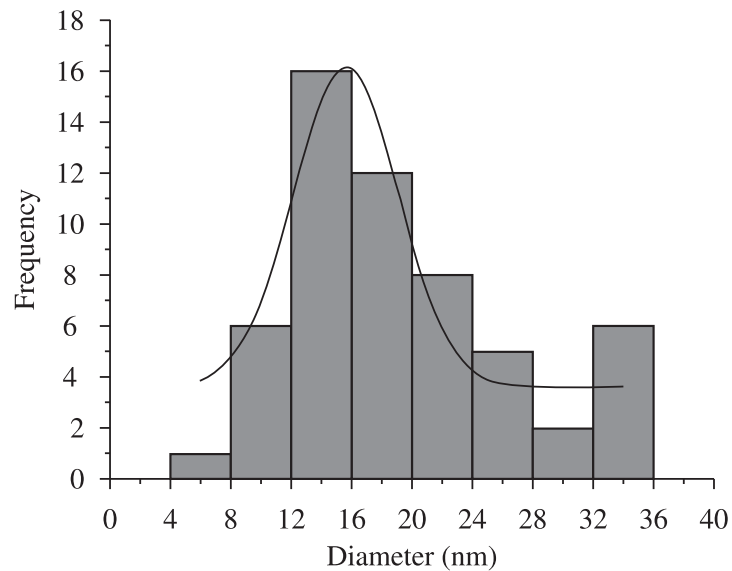

(c)

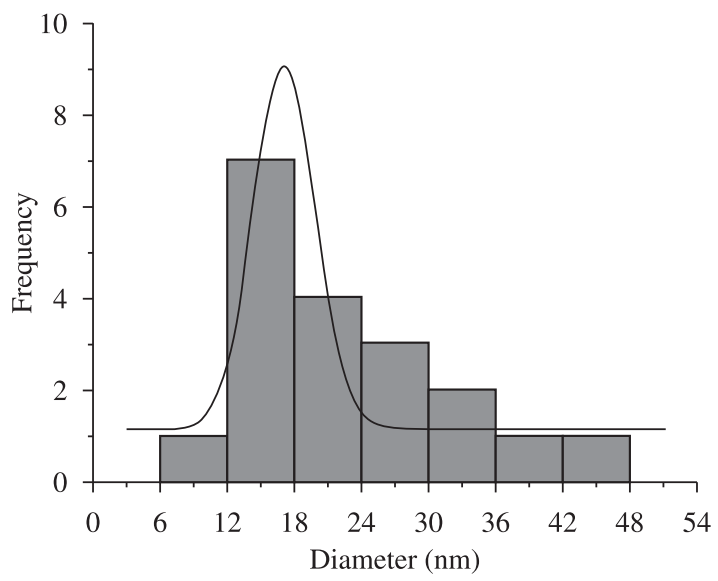

(f)

Figure 5. TEM images of the samples. a) Specimen 5\#; d) Specimen 6\#; b and e) their corresponding SAED patterns; c and f) the distribution of particle diameters determined from TEM of Specimen 5\# and 6\#, respectively. 


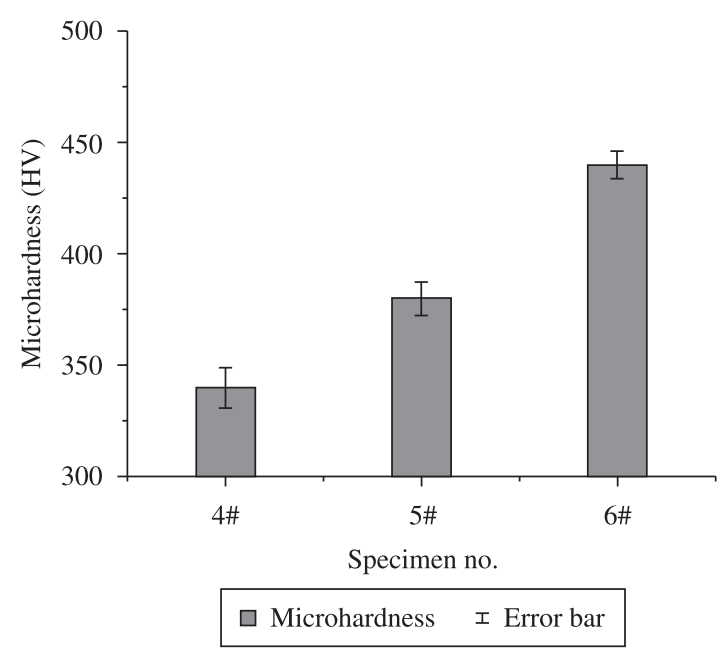

Figure 6. Micro-hardness of the nano-QCs.

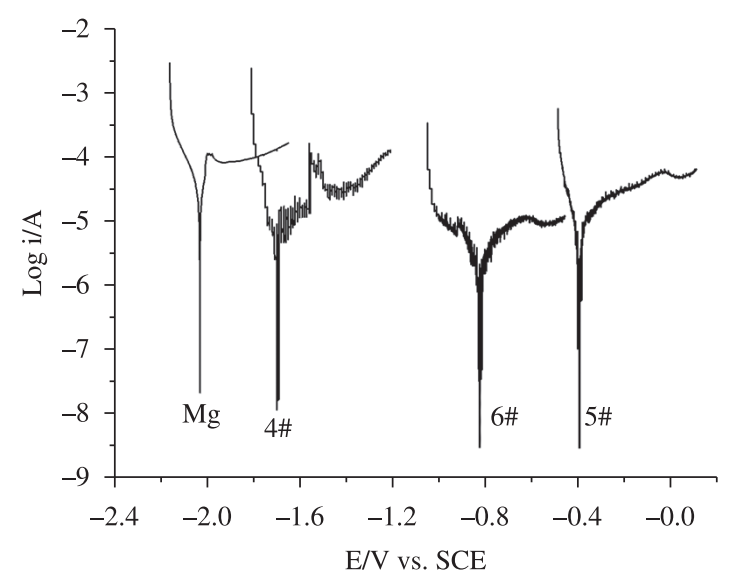

Figure 7. Potentiodynamic polarization curves of the specimen $4 \# \sim 6 \#$ measured in simulated seawater open to air at room temperature. A polarization curve of industrial magnesium is also shown for comparison.

Table 2. Corrosion parameters obtained from potentiodynamic polarization curves for specimen $4 \# \sim 6 \#$ in simulated seawater.

\begin{tabular}{ccccc}
\hline Specimen & $\mathbf{I}_{\text {corr }} / \mu \mathbf{A} / \mathbf{c m}^{-2}$ & $\mathbf{E}_{\text {corr }} / \mathbf{m V}$ & $\mathbf{R}_{\mathbf{p}} / \mathbf{k} \Omega$ & $\begin{array}{c}\text { Corrosion } \\
\text { rate/mpy }\end{array}$ \\
\hline $\mathrm{Mg}$ & 76.16 & -1675 & 6.073 & 34.8 \\
$4 \#$ & 11.09 & -1311 & 6.925 & 19.298 \\
$5 \#$ & 2.035 & -186.3 & 14.76 & 1.522 \\
$6 \#$ & 3.762 & -655.4 & 8.105 & 3.084 \\
\hline $\mathrm{E}_{\text {corr }}$ : corrosion potential; $\mathrm{I}_{\text {corr }}$ : corrosion current; $\mathrm{R}_{\mathrm{p}}$ : polarization resistance.
\end{tabular}

and reduce the crucial criteria radius for forming spherical QCs. However, increasing thermodynamics undercooling coming from wedge-shaped copper mold made it possible to form spherical $\mathrm{QCs}^{10}$. At the same time, the alloy components designed for this study is based on the three empirical rules ${ }^{17,18}$ for the formation of metallic glass. It has been widely accepted that quasicrystals and at least some metallic glasses are built up with icosahedral clusters ${ }^{19}$. On the tip of the wedge-shaped ingots, its cooling conditions is just suitable for these icosahedral clusters to be nucleation of QCs. And then, it leaves very short time for quasicrystal growth. So, it is nano-QCs that formed in this route instead of metallic glasses.

\subsection{Electrochemical properties of nano-QC alloys}

Figure 7 shows the potentiodynamic polarization curves of the specimen $4 \# \sim 6 \#$ measured in simulated seawater open to air at room temperature. A polarization curve of industrial magnesium is also shown for comparison. We can see that $\mathrm{Mg}_{72} \mathrm{Zn}_{26} \mathrm{Y}_{2}$ nano-QC alloy show higher corrosion resistance than industrial pure magnesium. Moreover, $\mathrm{Mg}_{71} \mathrm{Zn}_{26} \mathrm{Y}_{2} \mathrm{Cu}_{1}$ nano-QC alloy possess high corrosion resistance in simulated seawater and its corrosion resistance is much better than those of the $\mathrm{Mg}_{72} \mathrm{Zn}_{26} \mathrm{Y}_{2}$ and $\mathrm{Mg}_{71} \mathrm{Zn}_{26} \mathrm{Y}_{2} \mathrm{Cu}_{0.5} \mathrm{Ni}_{0.5}$ nano-QC alloys.

The key factor for the improved corrosion resistance of magnesium alloy can be ascribed to the formation of nano-QCs and Mg-Y intermetallics. These high corrosion resistance phases decreased the anodic passive current density, improved the polarization resistance and cut down the corrosion rate (Table 2). Although specimen $6 \#$ possess more and smaller nano-QCs than specimen 5\#, its corrosion resistance is lower than specimen 5\#. It was reported that when $\mathrm{Ni}$ and $\mathrm{Cu}$ have same contents in magnesium alloys, the damage level of them to the corrosion resistance of magnesium alloys is $\mathrm{Ni}>\mathrm{Cu}^{20}$. That is the reason for different corrosion resistance between specimen $5 \#$ and $6 \#$.

\section{Conclusions}

Mg-Zn-Y-based nano-QCs were synthesized by using a wedge-shaped copper mold in this paper. This is the first time that the stable $\mathrm{Mg}-\mathrm{Zn}$-Y-based nano-QCs were directly fabricated through a simple route instead of crystallization from metallic glasses or complicated forming processes at high temperature. Based on the fabrication and electrochemical experiments, the following important conclusions have been proposed:

- On the tips of the wedge-shaped ingots, the minimum diameter of nano-QCs approach to $4 \sim 6 \mathrm{~nm}$. The main size of nano-QCs is about $10 \sim 30 \mathrm{~nm}$. The maximum microhardness of QCs has been dramatically improved to about HV440 which increased by about $280 \%$ compared with that of the petal-like QCs fabricated under common cast iron mold cooling conditions;

- The forming mechanisms of nano-QCs were discussed from three aspects. Possessing a certain negative enthalpy of mixing and existence of FrankKasper-type phases determined the formation of $\mathrm{Mg}$ $\mathrm{Zn}$-Y-based nano-QCs. Under the suitable cooling rate, QC phases instead of metallic glasses or crystal phases can nucleate and grow in a very short time. And then, nanoscale QCs were formed;

- $\mathrm{Mg}_{71} \mathrm{Zn}_{26} \mathrm{Y}_{2} \mathrm{Cu}_{1}$ nano-QC alloy possess high corrosion resistance in simulated seawater and its corrosion resistance is much better than those of the $\mathrm{Mg}_{72} \mathrm{Zn}_{26} \mathrm{Y}_{2}$ 
and $\mathrm{Mg}_{71} \mathrm{Zn}_{26} \mathrm{Y}_{2} \mathrm{Cu}_{0.5} \mathrm{Ni}_{0.5}$ nano-QC alloys. The key factor for the improved corrosion resistance of magnesium alloy can be ascribed to the formation of nano-QCs and Mg-Y intermetallics. The corrosion resistance of $\mathrm{Mg}_{71} \mathrm{Zn}_{26} \mathrm{Y}_{2} \mathrm{Cu}_{0.5} \mathrm{Ni}_{0.5}$ nano-QC alloy is lower than $\mathrm{Mg}_{71} \mathrm{Zn}_{26} \mathrm{Y}_{2} \mathrm{Cu}_{1}$ nano-QC alloy. Because when $\mathrm{Ni}$ and $\mathrm{Cu}$ have same contents in magnesium alloys, the damage level of them to the corrosion resistance of magnesium alloys is $\mathrm{Ni}>\mathrm{Cu}$.

\section{References}

1. Thiel P. Quasicrystals-when all pieces fit together. Nature Materials. 2007; 6:11-12. PMid:17199119. http://dx.doi. org/10.1038/nmat 1814

2. Shechtman D, Blech I, Gratias D and Cahn JW. Metallic phase with long-range orientational order and no translational symmetry. Physical Review Letters. 1984; 53:1951-1953. http:// dx.doi.org/10.1103/PhysRevLett.53.1951

3. Saida J, Matsushita Mand Inoue A. Nano icosahedral quasicrystals in Zr-based glassy alloys. Intermetallics. 2002; 10:1089-1098. http://dx.doi.org/10.1016/S0966-9795(02)00142-5

4. Murty BS and Hono K. Nanoquasicrystallization of Zrbased metallic glasses. Materials Science and Engineering A. 2001; 312:253-261. http://dx.doi.org/10.1016/S09215093(00)01861-X

5. Galano M, Audebert F, Stone IC and Cantor B. Nanoquasicrystalline Al-Fe-Cr-based alloys. Part I: Phase transformations. Acta Materialia. 2009; 57:5107-5119. http://dx.doi.org/10.1016/j.actamat.2009.07.011

6. Liu Y, Yuan GY, Lu C, Ding WJ and Jiang JZ. The role of nanoquasicrystals on the ductility enhancement of as-extruded $\mathrm{Mg}-\mathrm{Zn}$-Gd alloy at elevated temperature. Journal of Materials Science. 2008; 43:5527-5533. http://dx.doi.org/10.1007/ s10853-008-2839-z

7. Kim DH, Lee JY, Lim HK, Kim WT and Kim DH. Effect of $\mathrm{Al}$ addition on the elevated temperature deformation behavior of Mg-Zn-Y alloy. Materials Science and Engineering A. 2008; 487:481-487. http://dx.doi.org/10.1016/j. msea.2007.10.031

8. Shi F, Yu YC, Guo XF, Zhang ZM and Li YY. Corrosion behavior of as-cast $\mathrm{Mg}_{68} \mathrm{Zn}_{28} \mathrm{Y}_{4}$ alloy with I-phase. Transactions of Nonferrous Metals Society of China. 2009; 19:1093-1097. http://dx.doi.org/10.1016/S1003-6326(08)60412-4

9. Izumi S, Yamasaki M and Kawamura Y. Relation between corrosion behavior and microstructure of $\mathrm{Mg}-\mathrm{Zn}-\mathrm{Y}$ alloys prepared by rapid solidification at various cooling rates. Corrosion Science. 2009; 51:395-402. http://dx.doi. org/10.1016/j.corsci.2008.11.003

10. Wang ZF, Zhao WM, Hur BY, Huang CY and Yu CQ. Effects of the fourth component and undercooling on morphology of primary $\mathrm{Mg}-\mathrm{Zn}-\mathrm{Y}$ icosahedral quasicrystal phase under normal casting conditions. China Foundry, 2009; 6(4):293-299.

\section{Acknowledgements}

The authors are pleased to acknowledge the financial support provided by Natural Science Foundation of Hebei Province, China (E2010000057) and International S \& T Cooperation Program of China (2010DFA51850). The authors are grateful to Dr. H.T. Fan of China National Academy of Nanotechnology \& Engineering for his kind help in TEM analysis.

11. Suarez MA, Alvarez O, Alvarez MA, Rodriguez RA, Valdez $S$ and Juarez JA. Characterization of microstructures obtained in wedge shaped A-Zn-Mg ingots. Journal of Alloys and Compounds. 2010; 492:373-377. http://dx.doi.org/10.1016/j. jallcom.2009.11.106

12. Wang ZF, Zhao WM, Li HP and Liang CY. Fabrication of quaternary $\mathrm{Mg}-\mathrm{Zn}$-Y-Ce quasicrystal alloys and their strengthening effects on AZ91 Magnesium alloys. China Foundry. 2010; 7:342-348.

13. Wang ZF, Zhao WM, Li HP, Ding J, Li YY and Liang CY. Effect of titanium, antimony, cerium and carbon nanotubes on the morphology and microhardness of Mg-based icosahedral quasicrystal phase. Journal of Materials Science \& Technology. 2010; 26:27-32. http://dx.doi.org/10.1016/ S1005-0302(10)60004-7

14. Wang ZF, Zhao WM, Lin XP and Hur BY. Effect of Mn and $\mathrm{Cu}$ on spheroidized process of $\mathrm{Mg}$-Zn-Y-based icosahedral quasicrystal phase. Advanced Materials Research. 2009; 79-82:1403-1406. http://dx.doi.org/10.4028/www.scientific. net/AMR.79-82.1403

15. Murty BS and Hono K. On the criteria for the formation of nanoquasicrystalline phase. Applied physics letters. 2004; 84:1674-1676. http://dx.doi.org/10.1063/1.1667265

16. Tsai AP. A test of Hume-Rothery rules for stable quasicrystals. Journal of Non-Crystalline Solids. 2004; 334-335:317-322. http://dx.doi.org/10.1016/j.jnoncrysol.2003.11.065

17. Inoue A. Stabilization of metallic supercooled liquid and bulk amorphous alloys. Acta materialia. 2000; 48:279-306. http://dx.doi.org/10.1016/S1359-6454(99)00300-6

18. Inoue A and Takeuchi A. Compotisions, structure and glassforming ability of bulk glassy alloys. Materials Science Forum, 2002; 403(2):1-12. http://dx.doi.org/10.4028/www. scientific.net/MSF.403.1

19. Dong C, Chen WR, Wang YM, Qiang JB, Wang Q, Lei Y et al. Formation of quasicrystals and metallic glasses in relation to icosahedral clusters. Journal of Non-Crystalline Solids. 2007; 353:3405. http://dx.doi.org/10.1016/j. jnoncrysol.2007.05.162

20. Song GL. Magnesium Corrosion and Protection. Beijing: Chemistry Industry Press; 2006. p.172. 